\title{
A population-based evaluation of a regional asthma education centre
}

\author{
Simone Cowan BScPhm MSc ${ }^{1}$, Pierre Ernst MD MSc FRCPC ${ }^{1}$,
}

André Cartier MD FRCPC ${ }^{2}$, Louis-Philippe Boulet MD FRCPC ${ }^{3}$

S Cowan, P Ernst, A Cartier, L-P Boulet. A population-based evaluation of a regional asthma education centre. Can Respir J 2004;11(1):39-44.

BACKGROUND: A population-based, ecological evaluation was conducted to determine the impact of a regional asthma education centre on reducing asthma-related morbidity and improving the quality of prescribing.

METHODS: The number of emergency department (ED) visits for respiratory-related illness and the prescribing of antiasthmatic medications were monitored during consecutive 18-month pre- and postintervention periods in two communities with similar health care resources. Using defined daily doses, the quality of prescribing was assessed by calculating the ratio of inhaled corticosteroids to inhaled, short-acting beta -agonists. $^{2}$

RESULTS: The reduction in the rate of respiratory-related ED visits in subjects five to 45 years of age was 410 per 10,000 people and 450 per 10,000 people for the intervention and nonintervention communities, respectively. A significant reduction in the rate of ED visits of 698 per 10,000 people was found for patients aged 35 to 45 years in the intervention community $(\mathrm{P}<0.05)$. The reduction achieved statistical significance in the nonintervention community in younger patients: 557 per 10,000 people and 567 per 10,000 people for patients aged five to 14 years and 15 to 24 years, respectively $(\mathrm{P}<0.05)$. The ratio of inhaled corticosteroids to inhaled beta agonists increased from 0.47 to 0.78 in the intervention community a $66 \%$ change. However, over the course of the preintervention period, the prescribing ratio was already increasing in this community. The corresponding ratios were 0.47 and 0.53 in the nonintervention community - an increase of $13 \%$.

CONCLUSIONS: A conclusive association between the establishment of an asthma education centre and changes in health care use or the quality of prescribing could not be demonstrated.

Key Words: Asthma education; Asthma therapy; Community interventions; Inhaled corticosteroids

In Canada, the morbidity and mortality associated with asthma remain high despite the availability of effective treatments $(1,2)$. Patient-centered education programs have been targeted as a strategy to reduce asthma-related morbidity (3). In the province of Quebec, an education network was developed with the goal of increasing the availability of and

\section{Une évaluation d'un centre régional d'éduca- tion sur l'asthme au sein de la population}

HISTORIQUE : Une évaluation écologique a été exécutée au sein de la population pour déterminer les effets d'un centre régional d'éducation sur l'asthme sur la réduction de la morbidité reliée à l'asthme et sur l'amélioration de la qualité des prescriptions.

MÉTHODOLOGIE : Le nombre de visites à l'urgence en raison d'une maladie reliée à des troubles respiratoires et la prescription d'antiasthmatiques ont été évalués pendant 18 mois consécutifs avant et après des périodes d'intervention dans deux collectivités disposant de ressources de santé similaires. À l'aide de doses quotidiennes définies, on a évalué la qualité des prescriptions en calculant le ratio de corticoïdes en aérosol par rapport aux béta ${ }_{2}$-agonistes en aérosol à action brève.

RÉSULTATS : La réduction du taux de visites à l'urgence en raison d'une maladie reliée à des troubles respiratoires chez des sujets de cinq à 45 ans était de 410 cas sur 10000 habitants et de 450 cas sur 10000 habitants au sein des collectivités interventionniste et non interventionniste, respectivement. Une diminution marquée du taux de visites à l'urgence de 698 cas sur 10000 habitants a été observée chez les patients de 35 à 45 ans au sein de la collectivité interventionniste $(\mathrm{P}<0,05)$. La réduction atteignait une signification statistique au sein de la collectivité non interventionniste de patients plus jeunes : 557 cas sur 10000 habitants et 567 cas sur 10000 habitants chez les patients de cinq à 14 ans et de 15 à 24 ans, respectivement $(\mathrm{P}<0,05)$. Le ratio de corticoïdes en aérosol par rapport aux béta 2 -agonistes en aérosol est passé de 0,47 à 0,78 au sein de la collectivité interventionniste, soit une augmentation de $66 \%$. Cependant, pendant la période précédant l'intervention, le taux de prescription augmentait déjà au sein de cette collectivité. Les ratios correspondants étaient de 0,47 et 0,53 au sein de la collectivité non interventionniste, soit une augmentation de $13 \%$.

CONCLUSIONS : Il a été impossible de démontrer une association concluante entre la création d'un centre d'éducation sur l'asthme et les modifications du recours aux services de santé ou de la qualité des prescriptions.

\footnotetext{
${ }^{1}$ Departments of Epidemiology and Biostatistics, and Division of Respiratory Medicine, McGill University Health Centre, McGill University, Montreal, Quebec; ${ }^{2}$ Service de Pneumologie, Hôpital du Sacré-Coeur, Montreal, Quebec; ${ }^{3}$ Institut de Cardiologie et de Pneumologie de l'Université Laval, Hôpital Laval, Sainte-Foy, Quebec

Correspondence and reprints: Dr Pierre Ernst, Royal Victoria Hospital, 687 Pine Avenue West, Ross 4.29, Division of Clinical Epidemiology, Montréal, Quebec H3A 1A1. Telephone 514-843-1564, fax 514-843-1493, e-mail pierre.ernst@clinepi.mcgill.ca
} 
Most studies evaluating the impact of asthma teaching programs have been conducted in tertiary care centres with good access to health care resources (5); few have evaluated the impact of these programs in an isolated primary care setting. Moreover, in terms of outcome measures, morbidity assessments have focused on the reduction of health care use $(6,7)$. Limited information is available on the changes in prescribing patterns associated with education programs, as well as the impact of such programs on morbidity and prescribing at a regional level. Accordingly, we assessed the population impact of an asthma education centre on reducing the number of respiratory-related emergency department (ED) visits and on improving the quality of prescribing in a rural primary care setting.

\section{Reference population and setting}

\section{PATIENTS AND METHODS}

Two geographically isolated regions in the province of Quebec (Antoine-Labelle and Iles-de-la-Madeleine) were selected for this population-based study. These two regions are similar in terms of age distribution (8) and sociodemographic indicators such as income and level of education (9). Both communities had access to family practitioners, either in private offices or at a community clinic, a local hospital and ED, and limited access to allergists and respirologists.

\section{Description of study design and intervention}

This study was designed as an ecological, community intervention evaluation using a pre- and post-test comparison. Baseline measurements of the number of respiratory-related ED visits and the quality of prescribing from January 1, 1995, to June 30, 1996, were collected retrospectively in both communities. Prospective, postintervention measurements of the outcome were measured from July 1, 1996, to December 31, 1997, encompassing the same seasonal periods as the preintervention measurements.

In May 1996, an accredited asthma teaching centre was implemented in the Iles-de-la-Madeleine community health centre to educate patients having severe, moderate and mild forms of asthma. Although the community health centre is supervised by a family physician, the education centre is staffed primarily by two registered nurses trained in providing education to patients with asthma. These same nurses also provide many other community health interventions. Patients with asthma are referred to the asthma teaching program by their physicians. The first educational session usually lasts from $60 \mathrm{~min}$ to $90 \mathrm{~min}$. Repeat sessions lasting $30 \mathrm{~min}$ to $45 \mathrm{~min}$ are scheduled on the basis of perceived need by the patient and nurse educator. Patients may have been seen in the physician's office, in the ED or on the hospital ward. In group and individual sessions, the program provides patients with information on the manifestations and mechanisms of asthma, avoiding asthma triggers and inducers, the goals of asthma treatment, medication use, side effects and inhaler technique. When ordered by a physician, instructional information on the use of an asthma action plan and a peak flow monitor is included. As warranted, progress reports are sent to the referring physician to communicate difficulties arising in asthma control or inhaler technique. Although the asthma education centre uses patient-focused teaching methods, physicians were invited to an introductory seminar on the goals and objectives of the teaching program and its role within the community; additionally, the centre functions as a resource site for health professionals with an interest in asthma education (4). The education centre is located in the community health centre next to the local hospital. Educational sessions were provided during regular working hours.

The Antoine-Labelle region served as the control community and had no formal asthma education centre during the study period except for the customary teaching programs already in place. Such programs included medication teaching in the community pharmacy setting, occasional site visits by respirologists and marketing activities by the various pharmaceutical companies.

\section{Study population}

All persons living in the two regions between the ages of five and 45 years comprised the study population. This age restriction was necessary to avoid confusing asthma with chronic obstructive pulmonary disease $(\mathrm{COPD})$ - a disease that generally occurs later in life - or with other wheezing illnesses that occur in young children $(10,11)$.

\section{Data collection and measurement}

Respiratory-related ED visits: The rate of visits to the ED for all respiratory-related illnesses was calculated for the pre- and postintervention periods. To obtain the numerator of the rate, all visits to the ED for respiratory-related illness were obtained from the ED registry at the sole hospital in each community. While a preexisting computerized service was available in Iles-de-laMadeleine, ED visits were manually collected in the Antoine-Labelle region by abstractors blinded to the research question. Importantly, respiratory-related illness was identified using the International Classification of Diseases, ninth edition (codes 33.0, 34.0, 460 to 519.9) (12), and was not limited to asthma-related ED visits to avoid the bias of diagnostic transfer (13). The denominator for the rate of ED visits was obtained using age-specific population sizes from the 1991 Canadian census for each region (8).

Prescriptions: All pharmacies in the Iles-de-la-Madeleine and Antoine-Labelle regions were approached to obtain consent to access their prescription records without the use of patient identifiers. Participation was obtained from all pharmacies, except for one in the nonintervention community (Antoine-Labelle). Using computerized abstracting services, complete prescription records were collected for all patients in the base population having a prescription for one or more beta-agonists (fenoterol, isoproterenol, orciprenaline, pirbuterol, procaterol, salbutamol, salmeterol or terbutaline) during the pre- or post-intervention periods. Persons with asthma were operationally defined as those having six or more prescriptions for inhaled, short-acting beta ${ }_{2}$-agonists during each 18-month period to identify patients with persistent symptoms during the pre- or postintervention periods.

The quality of prescribing was assessed by calculating the ratio of inhaled corticosteroid (beclomethasone, budesonide, flunisolide, fluticasone, triamcinolone) to inhaled beta $2_{2}$ agonist medications. To facilitate the aggregation of data across different types and formulations of medications, the World Health Organization defined daily dose system was used (14). From the quantity and strength of medications dispensed, and using the World Health Organization's standard for a specific medication type, the number of days of treatment was computed for each prescription dispensed (15). The number of treatment days were then aggregated within each class of medication - inhaled corticosteroid or beta ${ }_{2}$-agonist - to arrive at a single prescribing ratio for each community. Additionally, the prescribing ratio was plotted over sixmonth time intervals to characterize the growth of the ratio during the preintervention period. This analysis permits the assessment of 
TABLE 1

Reductions in the rate of respiratory-related emergency department (ED) visits

\begin{tabular}{|c|c|c|c|c|c|c|c|c|}
\hline Age (years) & \multicolumn{4}{|c|}{ Nonintervention community (Antoine-Labelle) } & \multicolumn{4}{|c|}{ Intervention community (Iles-de-la-Madeleine) } \\
\hline All & 19,200 & 3957 & 3093 & 450 & 8835 & 3529 & 3166 & 410 \\
\hline 15 to 24 & 3835 & 960 & 743 & $567^{*}$ & 2000 & 651 & 567 & 420 \\
\hline 25 to 34 & 5325 & 883 & 707 & 331 & 2610 & 777 & 707 & 268 \\
\hline 35 to 45 & 5280 & 816 & 610 & 390 & 2420 & 920 & 751 & $698^{*}$ \\
\hline
\end{tabular}

${ }^{*} P<0.05$, comparison of the rate reduction between the intervention and nonintervention communities

whether postintervention results were due solely to the continuation of a trend established during the preintervention phase.

\section{Statistical analyses}

A comparison of the changes in the rates of respiratory-related ED visits between the pre- and postintervention periods within each community was calculated using a two-sided test for proportions. The per cent change in the prescribing ratio from the pre- and postintervention periods was assessed within each community. Additionally, the average use of corticosteroids was expressed as a proportion of the available treatment days, and the difference between the proportions pre- and postintervention were compared within each community using a test for proportions.

\section{ED visits}

\section{RESULTS}

Table 1 outlines reductions in the rate of respiratory-related $\mathrm{ED}$ visits in the non-intervention and intervention regions of Antoine-Labelle and Iles-de-la-Madeleine, respectively. An overall reduction of $450 \mathrm{ED}$ visits per 10,000 people was observed in Antoine-Labelle. However, the rates in the preand post-intervention periods were not significantly statistically different. After stratifying by age, the largest rate reductions in Antoine-Labelle occurred in younger subjects - 557 per 10,000 people and 567 per 10,000 people in the five- to 14-year-old and 15- to 24-year-old age groups, respectively. A reduction of 410 ED visits per 10,000 people occurred in Ilesde-la-Madeleine. The rates in the pre- and postintervention periods were again not statistically different. The largest rate reduction (698 per 10,000 people) was found among individuals 35 to 45 years old.

\section{Prescribing}

During the pre- and postintervention periods, there were 425 and 436 persons, respectively, in the nonintervention region (Antoine-Labelle) who were eligible for the study of prescribing; of these, $50(11 \%)$ and $40(9 \%)$ met the operational definition of asthma (Table 2). Similarly, in the Iles-de-la-Madeleine region, $73(13 \%)$ and $55(10 \%)$ persons were enrolled during the pre- and postintervention periods, respectively, from an eligible population of 562 and 552 people. There was a higher proportion of male patients enrolled in the study of prescriptions in Antoine-Labelle - 52\% - compared with 42\% in Ilesde-la-Madeleine during the preintervention phase; these percentages were $62 \%$ and $42 \%$, respectively, during the postintervention period.
During the preintervention phase in Antoine-Labelle, the study population accumulated 13,674 days of inhaled beta agonist treatment in an 18-month period (Table 2). The use of

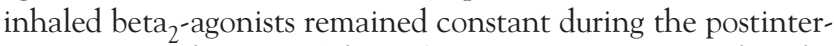
vention period - 10,935 days of treatment - meaning that the

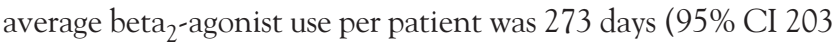
to 343 days) of treatment. The use of inhaled corticosteroids increased slightly in the postintervention period to an average of 145 days (95\% CI 85 to 205 days) of treatment per patient. Overall, this pattern of medication use corresponded to prescribing ratios of 0.47 and 0.53 , respectively, in the pre- and postintervention periods, yielding a $13 \%$ increase between the periods (Table 2). The average number of inhaled corticosteroid treatment days expressed as the proportion of available treatment days remained relatively constant at 23\% and $26 \%$ during the pre- and postintervention periods, respectively.

A total of 20,429 days of inhaled beta - -agonist treatment and 9634 days of inhaled corticosteroid treatment were accumulated in the Iles-de-la-Madeleine region during the preintervention phase. This represented an average of 280 days (95\% CI 245 to 315 days) and 132 days (95\% CI 92 to 172 days) of treatment per patient for inhaled beta ${ }_{2}$-agonists and inhaled corticosteroids, respectively. During the postintervention period, the average frequency of treatment increased to 290 days (95\% CI 249 to 331 days) and 227 days (95\% CI 157 to 297 days) of treatment for inhaled beta 2 -agonists and inhaled corticosteroids, respectively. These changes were reflected in the prescribing ratio, which increased $66 \%$ from 0.47 in the preintervention phase to 0.78 in the postintervention phase (Table 2). Expressed as a proportion of available treatment days, the average number of steroid treatment days rose significantly in the intervention community only, from $24 \%$ in the preintervention phase to $41 \%$ in the postintervention phase $(\mathrm{P}<0.001)$.

Figure 1 illustrates the change in the prescribing ratio over six-month intervals during the pre- and postintervention periods. In Antoine-Labelle, the preintervention period was characterized by fluctuations in the prescribing ratio, while in Iles-de-la-Madeleine, there was a consistent growth trend in the prescribing ratio, from 0.35 to 0.57 . During the preintervention phase alone, the prescribing ratio increased $63 \%$ in the intervention region, suggesting the possibility that the improvement in prescribing from the preintervention period to the postintervention period may be due to the continuation of a pre-existing growth trend and was, therefore, independent of the asthma teaching program. 
TABLE 2

Prescribing patterns in the intervention and nonintervention communities

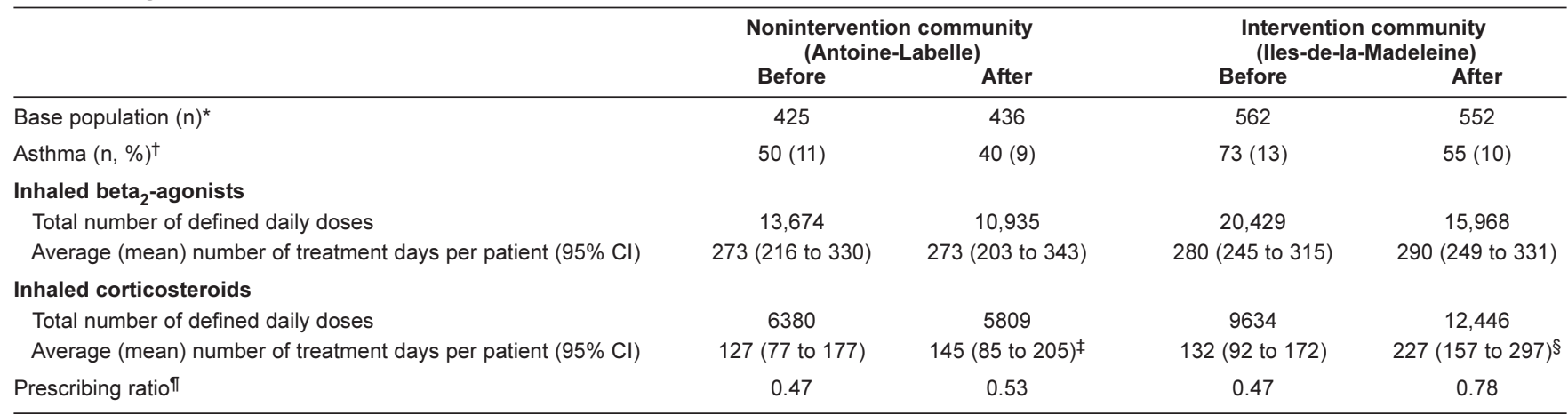

${ }^{*}$ Patients with one or more prescriptions for beta-agonists; ${ }^{\dagger}$ Patients from the base population with six or more prescriptions for beta-agonists; $¥$ Average number of corticosteroid treatment days is expressed as the proportion of available treatment days $(P>0.05) ;$; Average number of corticosteroid treatment days is expressed as the proportion of available treatment days $(P<0.05)$; "Ratio is the number of defined daily doses for inhaled corticosteroids $\div$ number of defined daily doses for inhaled beta $_{2}$-agonists

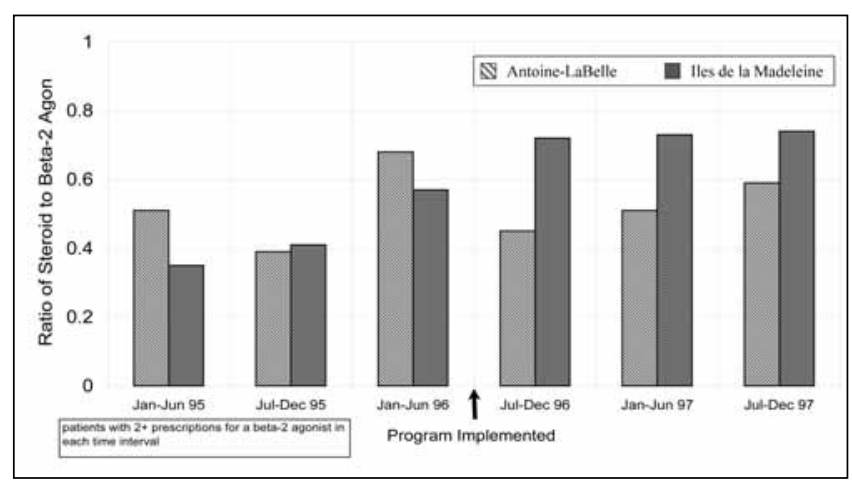

Figure 1) Change in the prescribing ratio over six-month intervals

\section{DISCUSSION}

Our study did not find a conclusive association between the establishment of the asthma education centre and a reduction in asthma-related morbidity or improvements in prescribing, although the use of inhaled corticosteroids continued to increase substantially in the intervention community over the period of time when the asthma education centre was present. Significant reductions in the rate of respiratory-related ED visits occurred in both the nonintervention and the intervention regions, with a more striking effect in the nonintervention community in terms of decreasing health care use among children and young adults - the segment of the population with the greatest asthma morbidity and mortality $(2,10)$. In the intervention community, the greatest decrease in the rate of respiratory-related $\mathrm{ED}$ visits occurred in patients aged 35 to 45 years. The decreases in morbidity observed in both communities point to the inherent weakness of the pre post study design and to the necessity of including a control community when assessing community interventions.

While patient education programs have been found to be effective in improving patient knowledge and compliance (16), studies evaluating the impact of asthma education centres on reducing health care use have drawn conflicting conclusions. Programs demonstrating the benefits of asthma education on behaviour and health care use are often conducted in specific patient populations with poor initial access to health care $(17)$, in those with severe disease $(18,19)$ or in tertiary care centres with good educational resources (5), thereby making these positive results difficult to extrapolate to other patient care settings. The contradictory nature of the available literature is further exemplified by studies obtaining negative results in the aforementioned patient groups (20), strengthening the argument that the effectiveness of a particular teaching program may be specific to its program-patient relationships $(7,21)$.

In terms of drug use, few studies have addressed the impact of education on prescribing patterns since the redirection in asthma treatment toward the use of inhaled corticosteroids and intermittent inhaled beta 2 -agonists. Evans et al (22) assessed the impact of an educational intervention for caregivers in improving the quality of care for pediatric patients with asthma. In the study, prescribing patterns of clinics in the intervention group demonstrated significantly greater adherence to the use of inhaled therapy and anti-inflammatory medications.

We chose to look at prescribing patterns as a measure of impact of asthma education, based on the emphasis of the education program on as-needed rescue use of beta-agonists and the central role of anti-inflammatory treatment in asthma management - concepts that we thought would be fed back to physicians by patients themselves, as well as by the nurses in terms of how well the patients were doing. While our study demonstrated a $66 \%$ increase in the prescribing ratio for patients in the intervention community, these findings may not have been associated with the establishment of the asthma education centre. We base this hypothesis on the fact that during the preintervention period, the use of inhaled corticosteroids was already increasing, as demonstrated by the $63 \%$ growth in the prescribing ratio of corticosteroids to beta ${ }_{2}$ agonists. An explanation for this increasing trend may lie in the preparatory activities needed to establish the asthma education centre, resulting in the sensitization of physicians to the importance of inhaled corticosteroids in the treatment of asthma. Furthermore, there has been a generalized increase in the use of inhaled corticosteroids for the treatment of asthma throughout the past decade. Finally, the smaller size of the community in Iles-de-la-Madeleine made average prescribing 
habits more susceptible to the influence of individual physicians.

We acknowledge that our study was subject to the limitations inherent to the ecological research design. Because data were available only at a population level, we were unable to directly assess the effectiveness of the education centre in changing the practices of individual patients and physicians. While it is possible that the benefits of the education centre were nullified or attenuated by the inclusion of data from patients without asthma, we believe this to be unlikely because special efforts were made to eliminate such patients. First, the study population was restricted to patients five to 45 years old to exclude those with COPD and pediatric wheezing conditions. Second, our definition of asthma in the assessment of prescribing, which selected for patients with six or more prescriptions for beta 2 -agonists during an 18-month period, was unlikely to include patients not having persistent asthma. Interestingly, trends in the prescribing ratio were independent of the number of beta 2 -agonists used to define asthma; similar prescribing ratios were obtained using the inclusion criterion of selecting patients with one to 10 prescriptions for beta ${ }_{2}$ agonists during the 18-month pre- and postintervention periods. In the assessment of hospital ED use, all respiratory-related diagnoses were collected to infer changes in asthma-related morbidity. Although this nonspecific measure of illness undoubtedly included patients without asthma, this global collection was necessary to avoid the bias of diagnostic transfer, in which trends in physician diagnosis and hospital coding practices may lead to temporal changes in the classification of asthma-related exacerbations (13).

Other difficulties encountered during the course of our study were unlikely to account for the direction of the results observed. Specifically, the incomplete participation of pharmacies in Antoine-Labelle would affect the study results only in the unlikely situation that nonparticipation was related to the community's nonintervention status and/or to factors affecting the quality of prescribing (23). Lastly, because we used pharmacy records to measure prescribing, any changes in drug use may be due to either changes in physician prescribing or patient compliance with previously prescribed therapy; nevertheless, both of these are desirable outcomes for our intervention.

\section{REFERENCES}

1. Mao Y, Semenciw R, Morrison H, MacWilliam L, Davies J, Wigle D. Increased rates of illness and death from asthma in Canada. CMAJ 1987;137:620-4.

2. Wilkins K, Mao Y. Trends in rates of admission to hospital and death from asthma among children and young adults in Canada during the 1980s. CMAJ 1993;148:185-90.

3. Ernst P, FitzGerald JM, Spier S. Canadian asthma consensus conference. Summary of recommendations. Can Respir J 1996;3:89-100.

4. Boulet LP, Chapman KR. Asthma education - The Canadian experience. Chest 1994;106:S206-10.

5. Fireman P, Friday GA, Gira C, et al. Teaching self-management skills to asthmatic children and their parents in an ambulatory care setting. Pediatrics 1981;68:341-8.

6. Howland J, Bauchner H, Adair R. The impact of pediatric asthma education on morbidity - Assessing the evidence. Chest 1988;94:964-9.

7. Bernard-Bonnin AC, Stachenko S, Bonin D, et al. Self-management teaching programs and morbidity of pediatric asthma: A metaanalysis. J Allergy Clin Immunol 1995;95:34-41.

8. Statistics Canada. 1991 Census of Canada, vol 1, Census Tracts. Selected characteristics for census divisions and census subdivisions, 1991 Census - 100\% data. Catalogue no 95-325. Ottawa: Ministry of Supply and Services, 1992.
A survey of attendance records from the asthma education centre revealed that the incomplete implementation of the conceptualized teaching program may partially explain our mainly negative findings. In total, 194 patients were referred to the clinic over a 10-month period (records of attendance were not kept for the entire study period), and 36\% of these were repeat participants. Consequently, only a small proportion of patients in this population-based study actually received the intervention. Furthermore, a recent meta-analysis suggests that an educational intervention aimed principally at enhancing knowledge does not improve asthma morbidity (24). Such improvements in morbidity likely require selfmonitoring and written action plans (25). The turnover of physicians in the intervention community may account for the relatively poor participation. New physicians did not benefit from the introductory asthma symposia and therefore probably had less knowledge of the programs offered at the asthma education centre. Furthermore, patients may have been referred for education but did not attend the session. Clearly, further research is needed into methods to increase physician and patient participation in all components of the asthma education centre. Following this, the effectiveness of the asthma education centre should be re-evaluated using a research design capable of collecting information at a patientspecific level.

\section{CONCLUSIONS}

The present study failed to find convincing evidence supporting an association between the implementation of an asthma education centre and a reduction in health care use or an improvement in prescribing practices. This finding may be related to the small number of patients seen at the asthma education centre and the absence of written action plans for the self-treatment of asthma. Future directions of the Quebec Asthma Education Network should focus on redefining program implementation strategies to produce a formula capable of affecting the morbidity, mortality and costs associated with asthma.

ACKNOWLEDGEMENTS: This research was funded by a grant from AstraZeneca Canada and l'Association Pulmonaire du Québec.

9. Statistics Canada. 1991 Census of Canada, vol 1, Census Tracts Selected characteristics for census divisions and census subdivisions, 1991 Census - 100\% data. Catalogue no 95-326. Ottawa: Ministry of Supply and Services, 1994.

10. Sears MR. Epidemiology of childhood asthma. Lancet 1997;350:1015-20.

11. Silverman M. Out of the mouths of babes and sucklings: Lessons from early childhood asthma. Thorax 1993;48:1200-4.

12. World Health Organization. Manual of the International Statisical Classification of Diseases, Injuries and Causes of Death, ninth revision. Geneva: World Health Organization, 1977.

13. Hyndman SJ, Williams DR, Merrill SL, Lipscombe JM, Palmer CR. Rates of admission to hospital for asthma. BMJ 1994;308:1596-600.

14. World Health Organization. Collaborating Centre for Drug Statistics Methodology. Anatomical Therapeutic Chemical (ATC) Classification Index Including Defined Daily Doses (DDDs) for Plain Substances. Oslo: World Health Organization, 1994.

15. Maxwell M, Heaney D, Howie JGR, et al. General-practice fundholding - Observations on prescribing patterns and costs using the defined daily dose method. BMJ 1993;307:1190-4. 
16. Mazzuca SA. Does patient education in chronic disease have therapeutic value? J Chronic Dis 1982;35:521-9.

17. Mayo PH, Richman J, Harris HW. Results of a program to reduce admissions for adult asthma. Ann Intern Med 1990;112:864-71.

18. Clark NM, Feldman CH, Evans D, et al. The impact of health education on frequency and cost of health care use by low income children with asthma. J Allergy Clin Immunol 1986;78:108-15.

19. Taggart VS, Zuckerman AE, Sly RM, et al. You can control asthma Evaluation of an asthma education-program for hospitalized innercity children. Patient Educ Couns 1991;17:35-47.

20. Shields MB, Griffith KA, McNabb W. The effect of a patient education program on emergency room use for inner-city children with asthma. Am J Public Health 1990;80:36-8.
21. Evans D. The impact of asthma health education programs on morbidity, use of emergency health care services and health care costs. Can Respir J 1996;3(Suppl A):17A-20A.

22. Evans D, Mellins RB, Lobach K, et al. Improving care for minority children with asthma: Professional education in public health clinics. Pediatrics 1997;99:157-64.

23. Hennekens C, Buring J. Epidemiology in Medicine. Boston: Little, Brown and Company,1987:171-2.

24. Gibson PG, Coughlan J, Wilson AJ, et al. Limited (information only) patient education programs for adults with asthma. Cochrane Database Syst Rev 2000;2:CD001005.

25. Gibson PG, Coughlan J, Wilson AJ, et al. Self-management education and regular practitioner review for adults with asthma. Cochrane Database Syst Rev 2000;2:CD001117. 


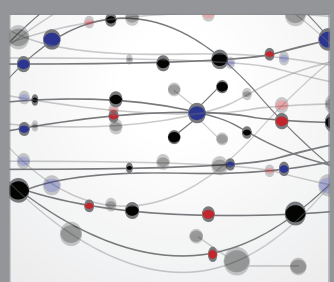

The Scientific World Journal
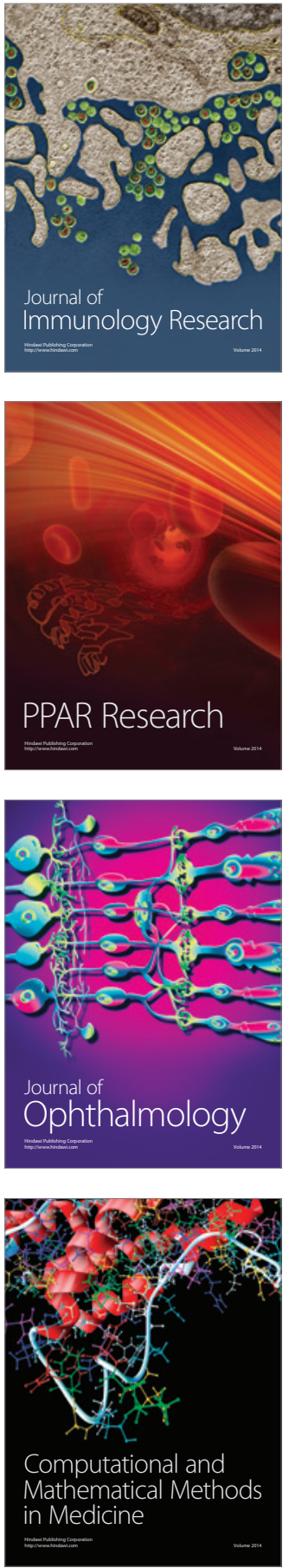

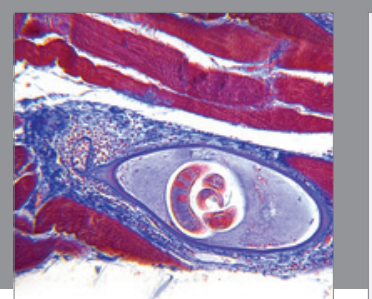

Gastroenterology Research and Practice

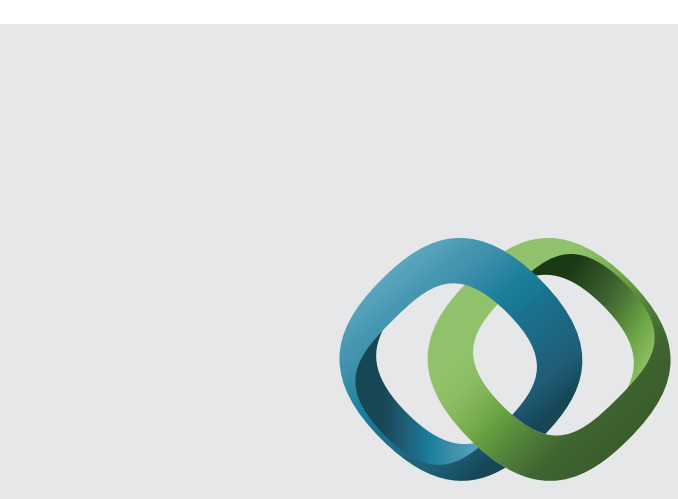

\section{Hindawi}

Submit your manuscripts at

http://www.hindawi.com
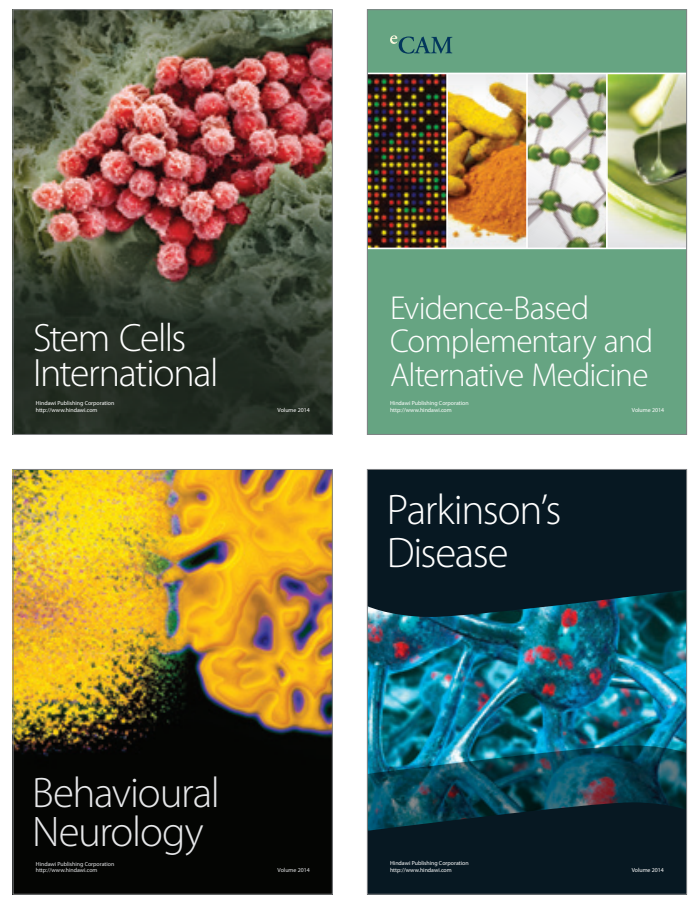
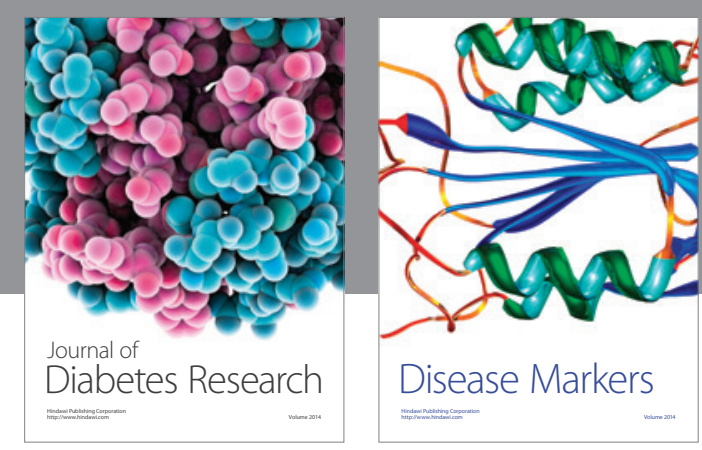

Disease Markers
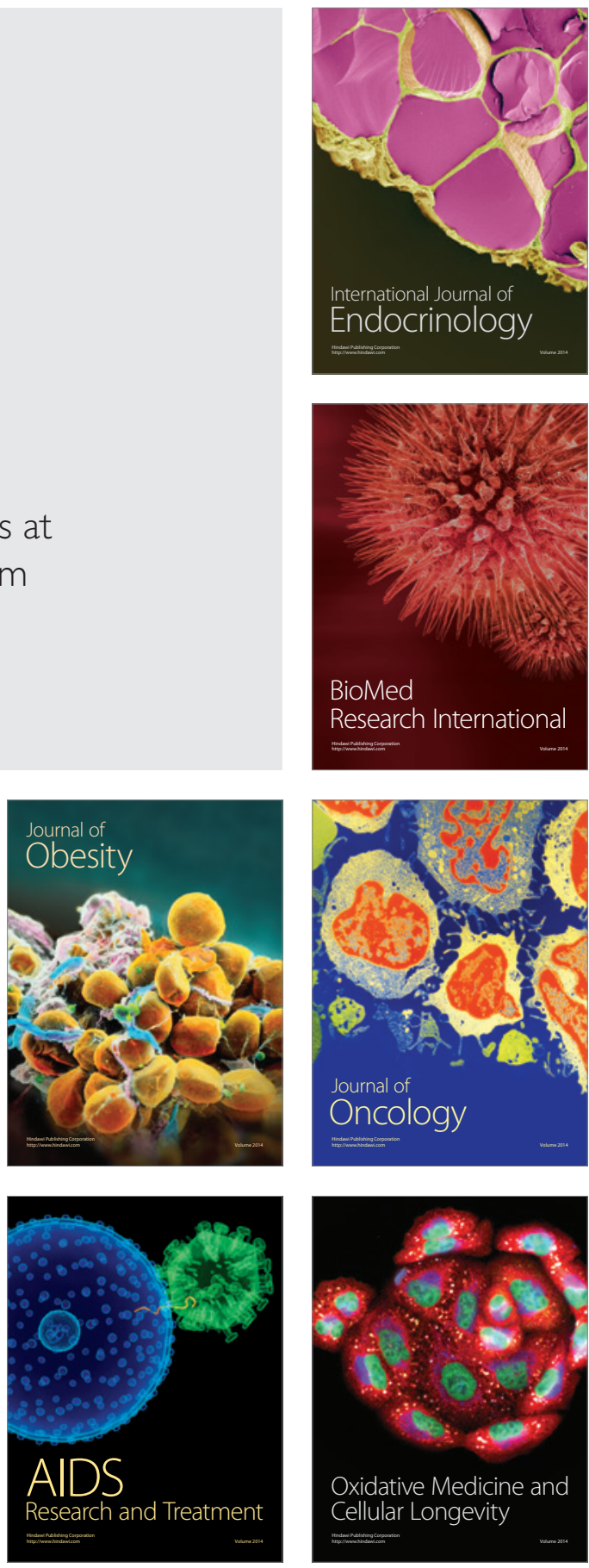